\title{
Andando com Paul Auster
}

Denilson Lopes

I am not here

This is not happening

Radiohead

Uma vez mais ele voltava a Nova Iorque. Não para ficar duas, três semanas de férias. Quase dez anos tinham se passado desde a última vez. Agora, ficaria novamente um ano. Poderia ter ido a outro lugar. Eram tantos os lugares que não conhecia, em que nunca estivera, nunca estará. Não era nostalgia, era uma outra viagem. Os amigos de outrora não mais presentes. Não mais as emoções desencontradas da primeira vez que ficara tanto tempo longe de casa, longe do Brasil. Outras novas emoções, diversamente desencontradas, certamente. Tinha a ilusão de se sentir mais livre, menos ansioso. Um novo desafio se apresentava, um salto, falar do outro, do centro, do cânone. Teria o que dizer? Em 2002, publicara seu último livro e, desde então, nenhum outro livro, a não ser ensaios, que tinha a ilusão de estarem construindo um outro livro, de uma outra forma, nem hipertexto de fragmentos, nem romance de ensaios autobiográficos, algo mais modesto, quadros de caminhadas e encontros de pessoas e personagens, imagens e lugares. Como antes, precisava de um fio condutor que não fosse apenas conceitual. A aposta agora era em Paul Auster, menos como obra e mais como ponto de partida para uma paisagem, ao mesmo tempo reconhecida e nova. Não, não era uma volta, queria olhar os olhos de Paul Auster, olhar com Paul Auster. Na chegada aos quarenta anos, sentia-se renovado, embora tudo parecesse familiar, estava aberto a esse outro desafio, essa outra procura.

Não foi difícil. Tinha marcado a entrevista em um café perto de sua casa, depois de sua caminhada diária. Com certa ansiedade, esperava. Tinha chegado cedo. Sempre costumava chegar cedo não importa a que encontro. Esse seria não apenas uma entrevista. Todos parecem estar tão ocupados hoje em dia, mas em uma fantasia, alimentada por seus livros, entrevistas, 
"(Auster, Paul. A arte da fome. Rio de Janeiro: José Olympio, 1996: 259) acreditava que ele teria tempo. Logo veio uma pequena decepção. Ele entrou rapidamente sem se sentar e o convidou para caminhar com ele. Estava começando algo mais inesperado ainda. No tempo em que ficou em Nova Iorque, no Brooklyn, de tempo em tempo, ele ligava, sempre ele. Se eu queria caminhar. Sempre disse sim. Não importava o que estava fazendo. Falavam muito no início. Com o tempo, as conversas foram ficando mais curtas e as caminhadas mais longas. Sempre tomavam uma rua e a seguiam, sem direção certa, a não ser o tempo, uma hora, um pouco mais. Tudo que vem a seguir seria outra coisa sem essas caminhadas, sobretudo as mais silenciosas, em que só havia o espaço do ar entre eles. Era como estar em casa. Passados tantos anos, ele não sabia se tudo tinha sido um sonho. Seria Paul Auster aquele que, pela primeira vez, atendeu o telefone? Com quem saíra? Ou não seria tudo fruto da leitura, esse "penetrar o mundo e encontrar seu lugar nele”* Que importa, ao fim e ao cabo, como se diz?

Ainda é possível caminhar nas ruas? Certamente, não como em um devaneio solto e bucólico, mas procurando resgatar a materialidade evanescente dos espaços diante da rapidez dos meios de transporte e comunicação, sobretudo do carro e da televisão: andar não com a cabeça nas nuvens, mas com os olhos abertos, a mente aberta, as energias concentradas em penetrar a vida ao seu redor. Trata-se da busca de um lugar onde "somente o limitado cotidiano está vivo"*. Exatamente nesse lugar a felicidade é encontrada, não em uma fuga ou transcendência deste mundo, embora este mundo seja extremanente frágil, mas misterioso em sua diversidade e potencialidade.

Há uma tradição norte-americana que, às vezes, pode parecer apagada pelas referências européias de Paul Auster, em particular francesas, seja sido tradutor do francês ou morado na França, como tantos outros escritores norte-americanos antes dele, seja a grande repercussão de seu trabalho tanto entre um público leitor mais amplo quanto na universidade. Essa tradição norte-americana traz uma herança democrática que precisa ser lembrada hoje em dia, desde Emerson, mas sobretudo Thoreau, sempre muito citado por Auster, que procura o sublime no rústico, por exemplo, na poesia de William Carlos Williams, que Auster também muito admira. Como seu personagem Peter Stilman em "Cidade de vidro", Paul Auster poderia dizer: "meus motivos são sublimes, mas minha obra, 
agora, tem lugar no reino do cotidiano"*. "Se não conseguimos sequer dominar um objeto trivial, cotidiano, que seguramos em nossa mão, como podemos pretender falar das coisas que nos dizem respeito mais a fundo?"*. O pequeno se torna uma estratégia provisória na busca de novas palavras adequadas a um novo mundo, em que o próprio escritor se torna "parte da cidade. Era um ponto preto, um sinal de pontuação, um tijolo em um infinito muro de tijolos"*.

Para pensar uma outra relação entre paisagem e narrativa é que ele se aproximou dos livros de Paul Auster. Suas narrativas sobre Nova Iorque, capital cultural da segunda metade do século XX, são um dos motivos de seu fascínio. Esse espaço de tantos romances e filmes encontrou em Trilogia de Nova Iorque uma recriação emoldurada na estrutura de romances policiais, mas que trata de questões existenciais, com personagens anônimos, sempre a um passo de desaparecer, de se perderem, uma constante em sua obra.

Nos escritos de Auster, há uma sutil história de Nova Iorque por meio de personagens comuns, uma singular contribuição à história do cotidiano atual, de um cotidiano povoado por concretudes e invisibilidades, potencialidades e desaparecimentos ${ }^{1}$. "Nada era real a não ser o acaso"*. Tudo parece tão banal, mas igualmente misterioso, talvez aí esteja seu maior aprendizado extraído dos romances policiais. E por mais que verdades sejam reveladas, isso nunca é o mais importante. Há um mistério que persiste e insiste mesmo depois da resolução de enigmas, quando os há. Como ele mesmo se define, trata-se de um realista marcado pela questão do acaso que define o mistério no mundo, sem cair na manipulação possibilitada pelas coincidências, como na ficção de má qualidade dos séculos XVIII e XIX, nem reproduzir os paradigmas do romance realista*.

No seu melhor, Auster não é o leitor da grande tradição moderna do romance, mas o poeta que deixou de ser quando começou a escrever romances, após uma década de tentativas frustradas, mas que o ajudaram a formatar sua narrativa povoada por paisagens, por personagens traduzidos por seus espaços,

\footnotetext{
${ }^{1}$ Seria interessante pensar o desaparecimento, "motivo central da ficção de Auster” [Gavillon, François. Paul Auster: gravité et légèreté de l'écriture. Rennes: Presses Universitaires de Rennes, 2000: 124] ], nas suas distinções e aproximações com o desaparecimento marcado pelo primado da velocidade associada a novas tecnologias em Virilio [Virilio, Paul. Esthétique de la disparition. Paris: Balland, 1980].
}

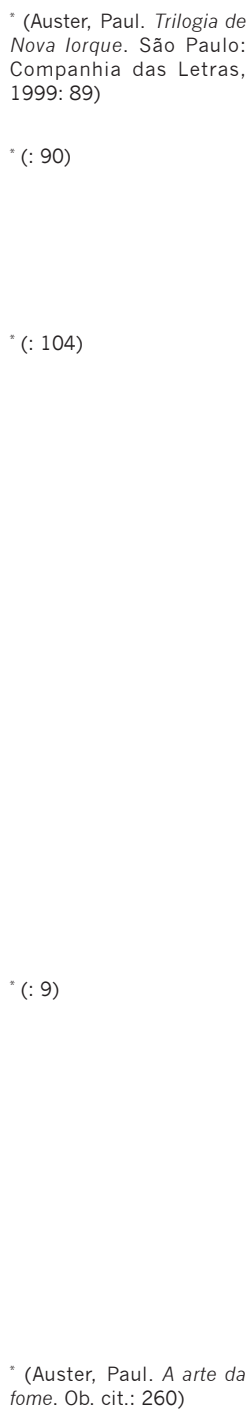

" (Auster, Paul. A arte da fome. Ob. cit.: 260) 
nos diálogos com pintores, dos paisagistas do século XIX que foram ao Oeste norte-americano aos quadros de Hopper sobre os espaços urbanos, à Land Art e ao encontro com Sophie Calle. Talvez Auster seja o melhor herdeiro dos jornalistas-cronistas do New Jornalism, obcecados não pela notícia, pela novidade, pelo extraordinário, mas pelo registro diário das coisas banais, mesmo diante de personagens excepcionais.

Comecemos pelo início. Se o grão não morre, quando o desejo de ser artista está no limiar, entre a promessa e a dúvida de ter ou não talento, quando, mesmo estando em Nova Iorque, encontra-se fora dos circuitos intelectuais e artísticos, o que acontece? Curiosamente, Auster enuncia uma estética da fome, "uma arte da fome”, para ser mais preciso. Não a fome do artista periférico que deglute tudo que vem de fora antropofagicamente, nem apenas a impossibilidade de sobreviver. "A arte da fome pode ser descrita como uma arte existencial. É uma forma de olhar a morte de frente, e com isso me refiro à morte como a vivemos hoje: sem Deus, sem esperança de salvação. A morte como o final abrupto e absurdo da vida"*. Uma arte que salva por acaso, como nos filmes de Kieslowski. O escritor se salva para a escrita e para o mundo não por uma vaga necessidade existencial, mas para sobreviver, e por meio de um golpe de sorte que lhe permite arriscar uma vez mais na escrita: o dinheiro recebido por herança paterna. Essa possibilidade salva também Auster de ser um sub-Kafka ou sub-Beckett, autores de sua predileção. O ritual de passagem para a visibilidade do escritor é o acerto de contas com o pai, “o homem invisível”, seu primeiro personagem, primeiro de uma série de personagens anônimos.

O fascínio pelo anonimato e pela invisibilidade também é encarnado em Reznikoff por sua humildade para com a linguagem e também para consigo mesmo*, por uma vida na obscuridade mas sem ressentimento": "Estou preocupado/ com as bobagens/ que falei./ Preciso de uma dieta/ de silêncio;/ fortalecer-me na quietude"*. Reznikoff é um estrangeiro que só encontra um lar em Nova Iorque. Auster talvez pudesse se encontrar em seu interesse por Reznikoff, como Joseph Mitchell na fala de Joe Gould, em um jogo de espelhos entre o jornalista bem-sucedido da New Torker, pai de família, e o vagabundo intelectual e fracassado em suas realizações e pretensões:

Em minha cidade natal, nunca me senti à vontade, escreveu certa vez. Eu destoava. Nem em minha própria casa eu me sentia em 
casa. Em Nova Iorque, principalmente no Greenwich Village, entre os maníacos, os desajustados, os que têm só um pulmão, os que já foram alguma coisa na vida, os que poderiam ter sido, os que gostariam de ser, os que nunca serão e os que só Deus sabe, sempre me senti à vontade*.

Para Auster, a cidade moderna é, por excelência, o espaço da invisibilidade, mais que do anonimato:

[...] somente na cidade moderna pode o observador permanecer invisível, assumir sua posição no espaço e, não obstante, permanecer transparente. Mesmo ao se tornar parte da paisagem onde entrou, ele continua sendo um forasteiro. Por conseguinte, objetivista. Quer dizer - criar um mundo ao redor de si vendo-o como um estranho faria. O que conta é a própria coisa, e a coisa vista só poderá adquirir vida quando seu observador tiver desaparecido. Nunca pode haver qualquer movimento em direção à posse. Ver é o esforço por criar presença: possuir uma coisa seria fazê-la desaparecer**

Então, será uma outra Nova Iorque que aparecerá nas páginas de Auster, não mais das vanguardas dos anos 1960, nem a cada vez mais pop e rica, paraíso yuppie dos anos 1980 , mas certamente sem o glamour da vida boêmia. Viver custa caro, particularmente em Nova Iorque. Não há muito tempo para paisagens espetaculares como na abertura de Manhattan, de Woody Allen, nem tempo para nostalgias. Tudo se eclipsa rápida e suavemente.

A invisibilidade está associada não só ao fascínio romântico pelo marginal, mas também à constituição de uma subjetividade e de uma paisagem, transpassadas pelos influxos do mundo, resposta ao excesso de informação e a estímulos de toda sorte.

Talvez mais do que a Nova Iorque de Trilogia de Nova Iorque, há uma outra que o chamou mais a atenção, vista um pouco enviesada, do Brooklyn, do outro lado da ponte, de onde veio também outro criador de paisagens, Paul Miller (DJ Spooky). Essa outra cidade aparece nos filmes que Paul Auster co-dirigiu com Wayne Wang: Smoke e sua continuação mais descompromissada, Blue in the face. Na tabacaria da esquina, seu dono passa os anos tirando fotos da mesma posição. As pessoas se tornam aparições, mesmo revelações, como a mulher falecida do amigo escritor. Ao mesmo tempo, as fotos são banais, umas entre tantas outras, mas podem se tornar significativas para quem olha. Em Smoke, são conjugadas a banalidade da narrativa e a poesia da paisagem. De certa forma, nele estão incorporadas preocupações presentes em vários filmes experimentais que procuraram
"(Mitchell, Joseph O segre. do de Joe Gould. São Paulo: Companhia das Letras, 2003: 33)

(Auster, Paul. A arte da fome. Ob. cit: 40) 
(Auster, Paul. O inventor da solidão. São Paulo: Best Seller, 1982: 8) registrar a banalidade e a passagem do tempo, de forma mais sensória e talvez mais difícil para o espectador médio, como Still, de Ernie Gehr, em que uma câmera fixa registra a passagem de um dia em uma rua, supostamente em Nova Iorque, estabelecendo essa passagem do tempo pela mudança do jogo de luz e sombras, e também pela superposição das imagens de pessoas e carros que passam com imagens refletidas, criando um jogo de fantasmagorias e simultaneidades.

$\mathrm{Na}$ tabacaria, lugar de passagem mas também de encontros, vários dramas de paternidade são encenados. A perda se transforma em desejo de procura, de reconstrução, de reencontro, de solidariedade, de amizade entre homens, como se fechasse o ciclo iniciado por Retrato do homem invisivel. À diferença de Paris, Texas, de Wim Wenders, em que o foco está no pai que reaparece, nesse breve e tocante texto de Auster, o foco está na perda irreparável causada pela morte do pai, mas que tornou possível sua vida como escritor, uma invisibilidade que possibilitou uma presença, por mais frágil que seja. Auster não silenciou como Joseph Mithcell depois de escrever seu último texto sobre Joseph Gould, nem ficou no anonimato como Reznikoff: construiu na literatura contemporânea, a partir dos anos 1980, uma das carreiras mais profícuas e bem-sucedidas junto ao público e à crítica. Não é, contudo, uma obra sobre os que chegaram lá, os que ganharam um lugar ao sol, ao som de New York, New York, na voz de Liza Minelli. Talvez por saber que, na indústria cultural, é bem mais fácil e provável descer, uma vez tendo subido, do que se manter visível. Como Suzanne Vega (lembram?) no auge da fama, falava: "Há um ano, tocava em bares, onde estava essa multidão? Ela pode também não estar aqui no ano que vem". Mais que consciência da fugacidade do mundo do entretenimento e de sua necessidade de fabricação de ídolos e stars, há uma forma de ver o mundo e uma poética que se constroem sobre a fragilidade pela invisibilidade.

Voltamos, então, ao seu primeiro personagem invisível. Misturam-se fotos e textos, fragmentos de memória. Se Rilke já nos preveniu: "As coisas desaparecem. Temos de nos apressar, se quisermos ver alguma coisa”, para Auster, a desaparição está tanto na cidade quanto no interior de casa: "Meu pai se foi. Se eu não agir depressa, toda a sua vida desaparecerá’*'. É dessa pressa, dessa premência quixotesca, que nasce esse texto dificilmente definido, entre a biografia e o romance, entre a imagem e a 
narrativa. O retrato de seu pai marca de forma indelével toda uma série de personagens semelhantes em sua ficção: "Isento de paixão, fosse por alguma coisa, pessoa, ou idéia, incapaz ou indesejoso de revelar-se em qualquer circunstância, ele conseguira manter-se à distância da vida, evitar a imersão na rapidez das coisas. Comia, ia para o trabalho, tinha amigos, jogava tênis, e apesar disso não estava ali. No sentido mais profundo e inabalável, era um homem invisível. Invisível aos outros, e muito provavelmente invisível a si mesmo"* .

Estranho em sua própria casa, "a verdade é que sua vida não girava em torno do lugar onde ele morava. A casa era apenas um dentre muitos pontos de escala numa existência inquieta e sem amarras, e essa ausência de centro teve como conseqüência transformá-lo num eterno estrangeiro, um turista em sua própria vida"* A casa parecia irreal, "mantida em ordem mas em processo de degradação", povoada por objetos de um morto.

Poderia parecer idiossincrático, mas não como freaks, e talvez como o protagonista de Straight story, de David Lynch, estranho e solitário em sua condição extremamente comum. Solitário. Mas não no sentido de estar só. Solitário não do modo como foi Thoreau, por exemplo, exilando-se para descobrir quem era; não à maneira de Jonas, rezando pela salvação no interior da baleia. Solitário no sentido de isolado. No sentido de não ter de enxergar a si mesmo, ou de não ter de "enxergar-se sendo enxergado por outra pessoa”* .

A herança paterna não é mais a do patriarcado, mas de ser uma sombra, talvez o destino do filho, o autor em formação. "Nosso destino é enfrentar o mundo tal como órfãos, perseguindo por longos longos anos as sombras de pais desaparecidos. Nada resta senão tentar levar a cabo nossas missões o melhor que pudermos, pois até o fazermos, calma alguma nos será permitida”* . Dessa forma, resume-se não só a procura do protagonista de Quando éramos órfãos, de Kazuo Ishiguro, mas também a orfandade como uma condição da subjetividade contemporânea. Também em Auster, a procura do pai marca sua escrita. No princípio havia o pai, ausência e invisibilidade. A morte do pai marca essa escrita órfã, frágil. O pai desaparece. Termina o relato. Da impossibilidade de dizer algo satisfatório sobre o pai, mas ainda assim de tê-lo feito, é que nasce um escritor.

Em Trilogia de Nova Iorque, logo em seu primeiro romance, "Cidade de vidro", temos já não mais um escritor em formação,
* (: 9) Longe do homem medíocre, um homem comum, imperceptível e discreto. 
"(Auster, Paul. Trilogia de Nova lorque. Ob. cit: 10)

mas um que está desaparecendo, que "já não existia mais para ninguém senão para si mesmo"*, não dava entrevistas, não estava em catálogo de escritores, sem amigos, com mulher e filho mortos. Nova Iorque aparece como lugar para se perder, não para conhecê-la melhor, como se fosse Walter Benjamin, mas para se transformar, ser outro, paisagem ideal para uma subjetividade não-centrada. A observação e as caminhadas lhe traziam "uma certa paz, um saudável vazio interior. O mundo estava fora dele, em volta, à frente, e a velocidade com que o mundo se modificava sem parar tornava impossível para Quinn deter-se em qualquer coisa por muito tempo"*. Nova Iorque era um lugar nenhum que Quinn não tinha desejo de deixar.

Curiosamente, ele só sai dessa mistura de luto e distanciamento, quando assume um outro nome, justamente Auster. "Sentiu uma serenidade extraordinária, como se tudo já tivesse acontecido com ele", "um homem sem interior nenhum, um homem sem pensamento", "uma casca sem conteúdo”*. Ser Paul Auster seria uma forma de Quinn se retirar de si mesmo, ser "mais leve e mais livre"*. Não se trata de ver o peso de ser outro, que pouco a pouco toma o protagonista de Profissão: repórter, de Antonioni, ao mudar de personalidade, nem simplesmente mais um personagem na esteira de Bartleby, de Melville, personagem da recusa, do não. Quinn, ao se nomear como Auster, deixa de ser escritor para ser investigador, passa a observar para estar no mundo: "Não fui contratado para entender, mas para agir"*.

Mas tudo muda quando finalmente encontra o "verdadeiro" Paul Auster, ao menos, o outro. Este identifica Quinn como escritor de poesia. Quinn se torna uma potencialidade de Auster, caso este tivesse perdido mulher e filho, caso sua carreira de escritor não tivesse sido tão bem-sucedida. Passamos a ver a contraface de Auster em Quinn, um vagabundo solitário, como Joseph Gould seria o outro lado de Joseph Mitchell.

Do mesmo modo que Peter Stilman, Quinn também desaparecerá. "Estar dentro daquela música, ser arrebatado para dentro do círculo das suas repetições: talvez esse seja um lugar onde possamos por fim desaparecer"* . Ao vigiar em vão o prédio de Stillman, Quinn cada vez mais precisava de menos coisas. "Ninguém jamais notou a presença de Quinn. Era como se ele tivesse se dissolvido nos muros da cidade"*. Por fim, acaba por se mudar para o apartamento vazio de Peter Stilman. Diante da consta- 
tação do constante desaparecimento, de nada adiantar a tarefa do detetive - "Tantas coisas estavam desaparecendo, era difícil seguir o rastro delas"* -, o livro termina com a constatação de mais um fracasso, mas também de uma libertação. "Nada mais importava agora, senão a beleza de tudo isso. Queria continuar a escrever sobre essas coisas e sofria por saber que não seria possível”**

"(143)

"(:146)

Em No país das últimas coisas, sai o diálogo com o romance policial, o filme noir, e entra o imaginário de uma ficção científica apocalíptica: prédios sendo destruídos e a cidade sem crianças, sem árvores (usadas para combustíveis), sem animais domésticos, sem pássaros, em um quadro de escassez, de falta de comida, de brigas inesperadas, em que pessoas magras são levadas pelo vento e metade da população é de desabrigados. Há cadáveres por todos os lados. A cidade deixa de ser Nova Iorque para ser um espaço ampliado da desaparição, ainda que algo existisse além de suas fronteiras. No meio das ruínas de uma cidade, pessoas que desaparecem, suposições que evanescem, sobreviver é o que importa: continuar caminhando, com pouca comida, em meio à fraqueza, à procura do irmão que desaparecera - esta é a perspectiva da protagonista. Diante da perda até da memória, é necessário saber desaparecer: "Nunca pense em nada, dizia. Simplesmente, dissolva-se na rua e finja que seu corpo não existe. Nada de meditações; nada de tristezas ou alegrias; nada a não ser a rua; esvazie-se por dentro, concentre unicamente no próximo passo a ser dado. Dentre todos os conselhos, esse foi o único que nunca cheguei a compreender"*.

Em meio a tanta precariedade o que subsiste é a fraternidade, representada pelo amor entre duas mulheres, como em Smoke a amizade entre os dois protagonistas, que diante da imponderabilidade de tudo, assemelha-se à fumaça de um cigarro que desaparece. Também no escrever não é possível mais o livro, uma obra total, restam cadernos e cartas, sem perspectiva de leitores: "Não tenho explicação. Só consigo narrar, não posso fingir compreender"*. "Estas são as últimas coisas, escreveu ela. Uma a uma, vão desaparecendo para nunca mais voltarem. Podia lhe falar nas que vi, nas que já não existem, mas duvido que haja tempo. Tudo vem acontecendo muito depressa, já não consigo reter os fatos"**.

Esse mundo em desamparo aparece com uma brecha em Palácio da lua, já presente no nome do protagonista, Fogel,
" (Auster, Paul. No país das últimas coisas. São Paulo: Best Seller, 1992: 54) 
(Auster, Paul. Palácio da lua. São Paulo: Best Seller, 1990: 11) que quer dizer pássaro: "Imaginei que algum bravo antepassado meu tivesse mesmo sido capaz de voar. Eu o via como um pássaro gigante que, em meio à névoa, atravessara o oceano sem parar, até chegar à América"*. É o verão de 1969, da chegada do homem à Lua, mas a Lua aqui também é do letreiro em neon do restaurante chinês, chamado justamente Palácio da lua. Próxima e distante, natural e artificial, devaneio e materialidade, essa é a paisagem ${ }^{2}$ contemporânea desse romance-síntese da obra de Auster, não mais à sombra dos gêneros, para além mesmo da memória da perda, da orfandade. Um romance de aventura, mas de uma aventura poética, como a viagem de Cyrano de Bergerac à Lua, uma aventura ambiciosa de refundação de um país, já presente na epígrafe de Jules Vernes: "Nada pode assombrar um americano". Ou como no biscoitinho chinês: "O sol é o passado; a terra o presente; a lua o futuro"*. Se não é possível ir à Lua, vai-se para o Oeste, atravessando o deserto até chegar a reencontrar a Lua, às margens do Pacífico. O protagonista se funde com a Lua, em um eclipse total, em uma transformação em uma paisagem que desaparece.

Mas para chegar a esse encontro poético, o protagonista experimentou a deriva por Nova Iorque como vagabundo até o encontro com Effing, mais uma figura paterna na ficção de Auster, pintor cego desaparecido, usando o nome de Julian Barber, fascinado pelo mundo das sensações, pelo ar na pele, pela luz invisível, "música do nosso avanço pelas ruas", em um mundo sem transcendência metafísica. É Effing quem recomenda a Fogg diante de um quadro: "Veja se consegue entrar na paisagem que está na sua frente. Veja se é capaz de penetrar na mente do artista que pintou aquela paisagem. Imagine que você é Blakelock a pintar aquele quadro"*. Como o vigia em Enigma de um dia, de Joel Pizzini, que nada fala diante do quadro, mas realiza uma viagem pelo mundo, como se esse fosse tela. Também é nesse sentido que podemos entender o encontro de Fogg com o deserto narrado por Effing e traduzido em uma "obra profundamente contemplativa, uma paisagem de intimismo e calma” com uma lua no meio*, ou talvez melhor,

${ }^{2}$ Para a importância do espaço na tradição do romance norte-americano, ver Pesso-Miquel, Catherine. "Sauts de puce sur la carte: discontinuité spatiale". Em: Toiles trouées et déserts lunaires dans Moon Palace, de Paul Auster. Paris: Sorbonne Nouvelle, 1996: 47. 
"não era uma paisagem, mas um momento, uma canção de luto por um mundo desaparecido"*.

No deserto, "lugar de silêncio, sem linguagem, última parte [dos Estados Unidos] a ser explorada", "tudo é volumoso demais para ser pintado ou sonhado; nem mesmo a fotografia consegue captar aquela atmosfera. Tudo é tão distorcido, é como tentar reproduzir as distâncias do espaço sideral; quanto mais se vê, menos o lápis é capaz de reproduzir. Ver aquilo é fazer com que desapareça”*. Não se trata apenas de um tema, de uma representação que nem os filmes conseguiram mostrar. "Como desenhar uma paisagem assim, toda igual? Entende o que estou dizendo, não é mesmo? Deixei de me sentir humano"** Trata-se de um novo aprendizado, de uma outra subjetividade. Ele "desaprendeu as regras que assimilara, confiando na paisagem, tratando-a como companheira, de igual para igual, abandonando voluntariamente suas intenções à força das singularidades, às investidas do acaso e da espontaneidade. Não mais temia o vazio ao redor. A tentativa de transpô-lo para a tela de algum modo o internalizara. Agora era capaz de sentir a indiferença desse vazio como algo que lhe pertencia, assim como ele pertencia ao poderoso silêncio daqueles espaços vastíssimos"* "Até lhe parecia, enquanto pintava, que a paisagem ia sumindo diante dos seus olhos"*. Trata-se de um real irreal. Esse aprendizado se traduz em uma libertação do mundo, mas dentro do mundo, para além de qualquer busca de origem. O futuro está na lua ou no ar, como previu Edgar Allan Poe.

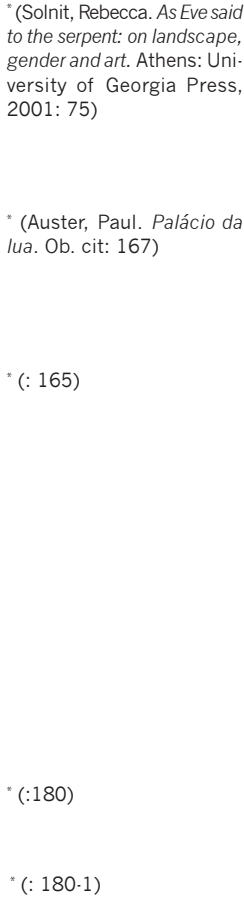


Denilson Lopes

Professor adjunto da Faculdade de Comunicação da Universidade de Brasília. Visiting Scholar da New York University. Doutor em Sociologia pela mesma universidade. Autor de Nós os mortos: melancolia e neo-barroco (Rio de Janeiro, 7 Letras, 1999), O homem que amava rapazes e outros ensaios (Rio de Janeiro, Aeroplano, 2002), co-editor de Imagem e diversidade sexual (São Paulo, Nojosa, 2004) e editor de $O$ cinema dos anos 1990 (Chapecó, Argos, 2005). No momento, finaliza livro sobre uma estética para a contemporaneidade. E-mail: noslined@unb.br

Palavras-chave Auster, paisagem, narrati va, invisibilidade, desapa recimento

Key words Auster, landscape, nar rative, invisibility, disap pearance.

Mots clés

Auster, paysage, récit, in visibilité, disparition

Recebido em $31 / 05 / 2005$

Aprovado em 30/06/2005

\section{Resumo}

Ensaio sobre a ficção de Paul Auster, procurando, com base na compreensão de como paisagem e narrativa se interligam, apresentar a invisibilidade e o desaparecimento como alternativas éticas e estéticas no mundo contemporâneo.

\section{Abstract}

Essay about the fiction of Paul Auster, searching from an understanding of how landscape and narrative intertwin themselves, present invisibility and disappearance as ethic and aesthetic alternatives in the contemporary world.

\section{Résumé}

À partir de la compréhension des rapports entre récit et paysage, cet essai sur la fiction de Paul Auster présente l'invisibilité et la disparition comme alternatives éthiques et esthétiques dans le monde contemporain. 